IN THE RED CROSS WORLD

\title{
FEDERAL REPUBLIC OF GERMANY
}

In the March issue of the periodical Deutsches Rotes Kreuz, Mr. M. W. Bargatzky, President of the National Red Cross Society, answered a number of questions concerning the Society's current welfare activities. In September and December 1974, the International Review published studies on the Red Cross and social work, and it seemed interesting therefore to supplement these by citing some of the answers given by Mr. Bargatzky:

The Red Cross in the Federal Republic of Germany seeks to institute and carry on social activities designed to meet the needs of people in our time, particularly in large cities. Most elderly people, for example, do not want to leave the places they live in and move into old people's homes. Accordingly, the services responsible for helping such people in the various local sections have been reinforced and now supply aid in various forms-portable tables for meals, housecleaning services, loans of books, regular visits and the organization of a specialized geriatric nursing service. The Red Cross is thus in a position to help these people in their own homes, to maintain their independence, save them from the sense of isolation and enable them to maintain normal human contacts.

The German Red Cross is also active in what might be called the field of "preventive social work". This consists, for example, of identifying and providing care as early as possible for children suffering from certain health deficiencies or some form of handicap; helping communities to "assimilate" new arrivals and facilitate the adaptation and integration of these people into their new and unfamiliar environment, thus avoiding many forms of tension and difficulty.

In carrying out this work, the Red Cross seeks to involve the population and to induce them to take initiatives and awaken them to their own social responsibilities. This was always a responsibility for the Red Cross, as indicated by the large number of its volunteers workers. One thing is increasingly obvious, however. Thanks to extensive comprehensive legislation, citizens are obtaining rights to social benefits. The application of that legislation and the drafting of new social legislation formerly depended largely upon the initiative of the authorities or of 
voluntary societies. This movement will continue, but it is recognized that there are an increasing number of areas in which laws count for very little, such as helping one's neighbour, to take the time to listen to one another's problems, to devote the time and energy to the many little acts of friendship.

This particular kind of assistance is especially needed in new housing developments, where people live in smaller rooms, are strangers to one another and find it difficult to adapt to their new conditions. The Red Cross intervenes in such cases to help establish better communication between such people and support their efforts in mutual help.

Lastly, the Red Cross is called upon to make a more direct contribution to social responsibility in the "Year for Voluntary Social Work". Every year, a thousand or so young people give their assistance in various fields of activity after intensive training for these tasks of human solidarity.

\section{PERU}

During the events which occurred in Lima on 5 February 1975, following a strike by the police force, some eighty Peruvian Red Cross first-aiders stationed on the main roads rendered effective assistance, sometimes at the risk of their own lives, to the injured before sending them by ambulance to one of the city's hospitals or dispensaries.

The National Society subsequently instituted a day-and-night firstaid service.

The International Review is glad to be able to report this illustration of the devoted spirit in which some National Societies act in time of trouble. 